\title{
Vulnerability to Depression in Mothers of Emotionally and Physically Handicapped Children
}

\author{
Dr. Fouzia Naeem Khan \\ SZABIST \\ Karachi, Pakistan
}

\begin{abstract}
In the present study, it was hypothesized that mothers of emotionally handicapped children will be more vulnerable to depression as compared to the mothers of physically handicapped children. In order to test these hypotheses, the Beck Depression Inventory (BDI) was given to 300 mothers. Sample was divided into 3 groups, 100 mothers of emotionally handicapped children, 100 mothers of physically handicapped children and 100 mothers of healthy children. Z-test was applied in order to get the statistical significance of the results. The results of the present study show that the mothers of emotionally handicapped children were more depressed than the mothers of physically handicapped children.
\end{abstract}

\section{INTRODUCTION}

A mother is one such family member who has received the lion's share of attention from researchers, theoreticians and clinicians. The evidence suggests that mothers are the primary or preferred attachment figures of young infants, who seek out their mothers when under stress. From shortly after birth, mother and father offer different types of experiences. During face-to-face play, fathers provide more unpredictable, less rhythmic, and more exciting (rather than calming) physical and vocal stimulation to their infants than mothers do [1], and in naturalistic play while fathers specialize in functional play [2]. In Western cultures as well as ours, mothers hold their babies most often for care taking purposes, whereas fathers hold their babies most often to play with them [3].

Before the birth of a child parents frequently develop an image, which reflects a variety of social and cultural ideas. Parents generally expect the newborn to be able to compete and achieve according to the norms and values of their own cultural group. Parent's relationship with their children is mostly of untiring love and affection. Obviously, their mental and emotional health is a great concern, which can cause serious behavior problems in the parents; especially in a mother, because mothers are usually, the primary care givers for infants and toddlers, which go on from childhood to adolescence in most of the cultures. Failure to give birth to a healthy and normal baby may induce a series of painful feelings and reactions in a woman. It is a well-known fact that any serious behavior problem can cause stress for parents, especially the mothers, as they are mostly responsible for the upkeep and development of their children.

Handicap in a child can be of an emotional nature or it can be a physical handicap. The mother of a physically handicapped child eventually accepts the deformity; as opposed to the mother of an emotionally handicapped child, who appears perfectly normal physically. The mother of the child finds it difficult to explain to the family in particular and society at large. Mothers often deny the emotional handicap, as they are ashamed of it [4].

The mother of an emotionally handicapped child is especially vulnerable to depression as she is already emotionally and physically depleted. There is numbness, shock and disbelief before a tentative awareness of the reality emerges, and she begins to feel disappointed and sad because of the sense of loss and despair. The feeling of helplessness, guilt, rage, anxiety and physical symptoms may occur repeatedly as denial. The grief of the mother will also be affected by her relationship with her spouse. If the husband is cooperative, her grief will automatically diminish and decrease. In the process of reexperiencing memories, expectation, and painful events; a parent achieves varying degrees of emotional acceptance. The balance of denial and acceptance is dynamic and occurs on many levels. The reality of the event is accepted rather than the current feelings and short-range implications.

There are various stresses, which many women face, due to their major responsibilities at home and work; social expectations also play a role here. Women's reproductive events, birth control measures and the decision of not having children often bring fluctuations in mood for some women, which ultimately result in depression [5]. Studies show that individuals with certain characteristics, pessimistic thinking, low self-esteem, a sense of having too excessive worrying, are more likely to develop depression. These attributes may heighten the effect of stressful events and interfere with any action being taken to cope with them. Some experts have suggested that the traditional upbringing of girls might foster these traits and that may be a factor in the higher rate of depression in women. Full significance of a serious handicap is often denied for a long time. Thus, parents of severely handicapped children may experience chronic sorrow.

Intellectual handicaps are especially hard to deal with, because they are often invisible, ambiguous, and unpredictable in the early years. The impact of the defect may only be evident latter. In these instances, longer periods of denial may result and mothers often experience repeated episodes of loss and grief, each time the defect becomes more apparent [6]. 
Failure to have a healthy and normal baby, parents especially mothers, may experience a series of painful feelings and reactions. Depression is one of the most commonly experienced reactions [7].

A handicapped child is usually disliked by other children at home, school and in the neighborhood. Adolescence brings added problems for an emotionally handicapped child, as mental and physical maturity increases his restlessness mounting frustration and depression in mothers. Mothers of emotionally handicapped children tended to be less mature and had lower levels of ego development. Such mother's ability to understand and accept an emotionally disturbed child relates to the development of her own personality as she deals with the varied stress situations that the introduction of a disturbed child into the family inevitably brings.

There are many different ways in which a mother can react emotionally to the fact that her child is emotionally or physically handicapped. The patterns of mother's behavior may vary from constructive form of adjustment (such as a realistic acceptance of the child's condition) to a destructive, maladaptive form of adjustment (such as rejection or denial of the handicapped). Reactions of mother's to a handicap child can be categorized in three major ways: she may accept, deny or disguise the child's handicap. Each mother reacts in her own unique manner to the stress situation created by the handicapped.

The mothers may react in a variety of ways to the stress situation resulting from the child's handicap. Maternal reactions are functions of many complex interacting variables. Some general maternal reactions include distorted perceptions of the capacities and qualities of the child, rejection tendencies, marital discords, narcissistic involvements, unwarranted reactions to the community, and feeling of guilt about the handicapped.

It is not unusual to find that the mother of the child is unable to perceive the reality of her child's handicap. She often sees the child as being quite different from what he actually is. Therefore, many family problems arise. Mother's difficulties in dealing with handicapped child can include:

- $\quad$ Setting of unrealistically high goals for the young child

- Over protection of the child

- Over indulgence of the child

- Maladjustment of the mothers, manifested in alcoholism or emotional disturbance [8]

The handicapped child, particularly at a young age, does demand more than the usual amount of attention and care. It is usually the responsibility of the mother to provide this. However, the father may often resent the fact that his wife pays more attention to the child than she does to him, so he tends to react with hostility towards both his wife and his child - towards the wife for rejecting him, and towards the child because of the demands upon the mother. Such a reaction is more apt to occur when the husband is immature and infantile.

The mother of the handicapped child often feels that the child's condition in some way is due to some past action of her own. Such a reaction stems directly from the mother's guilt feelings, which may be aroused by the disabilities of the child. The person who constantly feels guilty has a lower self-percept and tends to see himself in an unfavorable light. When guilt feelings are strong, the person feels insecure. In short, her self-esteem is lowered and she becomes vulnerable to depression [9].

Initially, the reaction ranges from anxiety, resentment, and a deep sense of inadequacy, guilt and depression to over protectiveness and over indulgence. Denial of the disability and its permanent nature is the most common psychological reaction. This is often the most common cause of parent's inconsistency in treatment and rehabilitation. Guilt is another important emotion that the mother feels. This is often displaced and projected on to the medical staff in the form of argumentative, uncooperative and even aggressive behavior. The mother also tends to avoid appropriate discipline and control on the child for the fear of aggravation of the child's illness [10]. With a physical handicapped child, the stress on the family usually begins at the child's birth or shortly thereafter [11].

The present study has been conducted in Pakistan to find out the vulnerability to depression in mothers of emotionally handicapped children. While framing the hypothesis, cultural patterns and various other factors prevalent in Pakistan were also kept in mind. Keeping in view the theoretical and literature review, the following hypotheses were formulated:

- The mothers of emotionally handicapped children will be more depressed than the mothers of physically handicapped children

- The mothers of emotionally handicapped children will be more depressed than the mothers of healthy children

- The mothers of physically handicapped children will be more depressed than the mothers of healthy children

\section{METHODOLOGY}

\subsection{Participants}

This study was conducted to assess the depression level of the mothers of emotionally and physically handicapped children in Pakistan. In order to analyze it scientifically, the mothers of emotionally handicapped children were compared with the mothers of physically handicapped children and mothers of healthy children. 
A total of three hundred subjects were selected for the study, out of which total hundred women were selected for each group, viz., emotionally handicapped children, physically handicapped and normal and healthy children, respectively.

The handicapped children were selected from the institutions, hospitals and schools of Karachi; where they are studying or being treated. The ages of these children ranged from 6-12 years.

\subsection{Procedure}

The Beck Depression Inventory (BDI) was individually administrated to the subjects in a standard manner and they were assured of confidentiality. After that, the following demographic information was collected from each subject:

- Age

- Education

- Occupation (if any)

- Family income from all sources

- Place of residence

For the purpose of the study, a score of 17 on BDI was considered as the cut off score. All participants whose scores on BDI fell below 17 were considered nondepressed and all participants whose score on BDI fell above 17 were labeled as depressed.

\subsection{Interview Measures}

Beck Depression Inventory was used as interview measures. This is a 21 items, self-report scale used to assess cognitive and physical symptoms of depression. It has been used extensively in psychological research with numerous populations and psychiatric disorders, including PTSD. The split half reliability of BDI is .93, it has been found to be correlated with clinician rating of depression. The BDI was self administered in the study with assistance from interviewer when needed and was calculated following Beck's original cutting point for a normal population.

\subsection{Statistical Analysis}

Z - Test was computed to investigate whether or not there was significant difference between the vulnerability to depression in mothers of emotionally and physically handicapped children.

\subsection{Definitions of Different Variables}

Emotionally Handicapped: A person suffering from emotional handicap is naughty, mischievous, troublesome and difficult to manage in the class. His aggression, anger, rage etc. seem to be utterly out of his control. His temperament is fiery and inconsistent, and he is unpredictable. A less socially based definition is inability to cope with one's environment. It can be defined as the state of having severely distorted behavior, thought or feeling. All the handicaps, which originate in organic lesions, are excluded from the definition of an emotionally handicapped.

Physically Handicapped: A child suffering from any physical defect, which impedes his educational, vocational, emotional or social adjustment is referred to as a physically handicapped child. A physical defect may be congenital. It may on the other hand be acquired through disease or accident. The group of physically handicapped children includes those children who are crippled, blind or partially sighted, deaf, hard of hearing, defective in speech, epileptic and vitally low; that is cardiac, allergic, diabetic and malnourished. A physical handicap is a disability of anatomy, function, or appearance; these can be detected in infancy and later in life.

\section{RESULTS}

Hypothesis No. 1: "The mothers of emotionally handicapped children will be more depressed than the mothers of physically handicapped children”.

The results indicate that $\mathrm{Z}=7.374, \mathrm{n}_{1}=100, \mathrm{n}_{2}=100$; which shows that there is significant difference between the two groups. This is pointing to the fact that mothers of emotionally handicapped children are more depressed than the mothers of physically handicapped children.

Hypothesis No. 2: “The mothers of emotionally handicapped children will be more depressed than the mothers of healthy children”.

The results indicate that $\mathrm{Z}=25.58, \mathrm{n}_{1}=100, \mathrm{n}_{2}=100$; which shows that there is significant difference between the two groups. This is pointing to the fact that mothers of emotionally handicapped children are more depressed than the mothers of healthy children.

Hypothesis No. 3: "The mothers of physically handicapped children will be more depressed than the mothers of healthy children”.

The results indicate that $\mathrm{Z}=23.49, \mathrm{n} 1=100, \mathrm{n} 2=100$; which shows that there is significant difference between the two groups. This is pointing to the fact that mothers of physically handicapped children are more depressed than the mothers of healthy children.

\section{DISCUSSION}

The theoretical and practical observations have brought to light the fact that mothers of emotionally and physically handicapped children are more depressed than the mothers of healthy children. Obviously, it is a fact that the mothers have to look after the children more intimately and are responsible for training and upkeep of the children. It is, therefore, not surprising that the mothers of 
handicapped children will be more depressed than the mothers of healthy children.

It is well known that whatever research is available has been conducted in developed countries. So far, no research has been conducted in Pakistan to explore the factors, which makes a mother vulnerable to depression while having an emotionally handicapped child.

It is absolutely imperative for us to know as to what are the various characteristics of women, which makes her vulnerable to depression. What are the psychological reactions of mothers of a handicapped child and whether the psychological reactions differ for both the emotional and physically handicapped?

The results obtained indicated that there is a positive relationship between the mental health of children and the depression of mothers.

This study was undertaken to find out whether mothers of emotionally handicapped children are more vulnerable to depression than the mothers of physically handicapped children.

Like many other countries in the developing world, mental health remains perhaps the most neglected sector of health and health care delivery in Pakistan. The country gives a low priority to its public health services in general, and among the services available, mental health is given still a lower priority.

Hypothesis No. 1 states, "The mothers of emotionally handicapped children will be more depressed than the mothers of physically handicapped children”. This hypothesis is supported by the data and is statistically significant at $\mathrm{P}$ less than 0.05 levels.

The mean scores for mothers of emotionally handicapped children are more than the mothers of physically handicapped children. Hence, it is clear that the mothers of emotionally handicapped children are more depressed than the mothers of physically handicapped children.

In Pakistan, most of the people are not aware of the problems of emotionally handicapped children; therefore, every child who suffers from emotional problems is generally attributed to a lack of interest shown by mothers in childcare. The reason that people hold mothers responsible for the emotional handicap can be due to lack of awareness about the etiology of emotional handicap as compared to that of physical handicap.

In case of a physically handicapped child, people generally sympathize with parents; while in the case of an emotionally handicapped child, parents-specially mothers stand vulnerable and are criticized by the people around them about the irritable attitude of their child.
People react in many ways to someone with a history of mental problem. They dislike such a person, their perception of him/her changes in a uniformly negative direction, and they behave differently and generally less favorably towards the person. This not only affects the individual's behavior but most of the time greatly influences parents, especially a mother's feelings and behavior. It may be possible that the mother of such a child faces more difficulties in social relationships, thus predisposing them towards frustration, dissatisfaction and emotional turmoil.

When the mother comes to know about the emotional problems of her child, she starts to blame herself; feeling guilt, embarrassment accompanied by a sense of loss and grief. After experiencing the shock, the feelings are replaced by numbness, followed by denial, anger and helplessness. The crucial stage is where the mother has to adjust her self; failure to do so, makes her more vulnerable to mental illness, especially depression.

A mother's attempt to disguise the nature of a situation that the family was totally unable to accept, imply that she perceived the child's disabilities as threatening to herself and that she had a deep sense of shame. Thus, such mothers are clearly unable to cope with the problems of the handicapped child. She refuses to accept the recommendation of either the schoolteacher or the tutors. The depression engendered by her reactions to the handicap, impact many of her social interactions and as a result, she tends to isolate herself from other people.

The emotional reactions of the handicapped child's parents are usually maladaptive. The father cannot accept the reality of his child's handicap. As the situation becomes progressively worse, he begins to blame his wife for the problems, which inculcate severe feelings of guilt and depression in the mother. Neither the mother nor the father has insight into the fact that their problems did not stem from their relationship, but rather, from their continuing frustration in being unable to cope with the stresses related to the child's condition.

Mothers of the children with greater limitations in their normal functioning are more likely to perceive their roles restricted and are more likely to be depressed than are mothers of children with less severe functional limitations.

Role restriction and children's functional limitations are identifiable and measurable factors that directly relate to maternal distress and may help to distinguish mothers of children with chronic conditions, who are at increased risk of psychological disturbance.

Improving role restriction in mothers by providing additional resources, through the health care system, is an opportunity for public policy based intervention. Efforts focused on improving mother's mental health are likely to have important implications for preventing adjustment problems in their children as well. 
There appears to be a developmental process through which the parents usually pass before adequately recognizing and accepting the problems of their child. There is a pattern of growing comprehension as the parent gradually becomes aware of those problems. Hence, it can be stated that there is a phase of awareness when the mother perceives the child as being different in some way from the other children.

The mother recognizes what exactly the problem is with the child. There is a phase in which the mother seeks a solution, taking the child from person to person, talking to all whom she perceives as possibly being of help. Finally, there comes a stage when she accepts the situation. The progression of the mother through these phases is not automatic. The adequate process of psychological growth of a mother depends not only upon the basic emotional maturity of the mother her self, but also upon the guidance that she receives in coping with the problems involved.

People in our culture are not aware of the help, which they can receive for emotional handicap. It is source of relief that for the last few years, with the establishment of various hospitals and institutes, people with emotionally handicapped children can go and receive help from such places.

Hypothesis No. 2 states, "The mothers of emotionally handicapped children will be more depressed than the mothers of healthy children". This hypothesis is supported by the data and is statistically significant at $\mathrm{P}$ less than 0.05 levels.

It is apparent that the emotional maladjustment of the mother is reflected in her behavior towards the handicapped child. In many instances, the mother tries to adopt patterns of rigid and persistent discipline and training at home, because she feels that such action will help the child. She cannot see that they block off the possible fantasy life of the child and lead to more severe emotional disturbances.

Because a mother's rejection of the child is frequently unconscious, the mother is not aware of the basis of her own feelings towards the child. Consequently, the mother experiences severe conflicts. These, of course, depend upon her personality characteristics.

When a mother discovers that her child is handicapped, particularly if there are emotional symptoms that can be regarded as a stigma, it becomes emotionally traumatic, which she senses as bereavement. This is some thing followed by a continuing state. In this condition, the mother fails to adopt suitable strategies for dealing with the problem in a realistic manner. In general, the tragic crisis reaction is more typical of families of high social and economic status. The role crisis is more typical of families of low social and economic status.
The mother's emotional reaction to the handicapped child may be so severe as to result in a psychopathological reaction. However, the primary cause of such a maternal reaction is not the condition of the child per se; rather, it is the severe problems of the mother herself. The added stresses to which the mother is subjected and the additional problems created for her by the child intensify existing depression and precipitate her own severe emotional problems.

It might well be that, without the added stresses caused by the child; the mother might have been able to defend herself enough to hold the psycho-pathological reaction in abeyance. The more conflicted and unstable the mother is (because of her own internal problems), the more apt she is to react in a maladaptive way to the additional problems created by the child. The degree and severity of the resultant emotional reactions of the mother are proportional to her own emotional instability. The most usual maladaptive reaction is the development of a psychoneurosis, but a psychotic reaction may occasionally develop. The onset of depression is more frequent among psychoneurosis.

It is very interesting to note that mothers of healthy children from similar backgrounds are healthier than the mothers of emotionally handicapped children.

Hypothesis No. 3 states, "The mothers of physically handicapped children will be more depressed than the mothers of healthy children". This hypothesis is supported by the data and is statistically significant at P less than 0.05 levels.

Early maternal reaction to physically handicapped child initially ranges from anxiety and resentment. Denial is the most common psychological reaction. Mothers deny the child's handicap, which is most common cause of a mother's inconsistency in treatment and rehabilitation.

Mothers also tend to avoid appropriate discipline and control on the child for the fear of aggravation of the child's illness.

Some mothers have a clear insight into the child's problem, for such reasons, she seeks competent guidance to help her solve the complex problems. Such mothers are well aware of their child's disabilities and accept him as a person in his own right and are able to acknowledge him as a full member of the family group. This illustrates positive, constructive attitudes of mothers who are accepting the problems of their child, but unfortunately such pictures are very rare in Pakistan.

Mostly mothers do not perceive the difficulties of their handicapped child and, hence, are unable to understand his/her limitations. She perceives her child as bringing shame and tries to hide her feelings naturally from the child itself and other people. When the child in not doing well at school, she blames the school and refers 
him/her lazy and uncooperative. The mothers of healthy children do not go through such problems and are free from mental problems themselves.

\section{CONCLUSION}

Emotional problems, especially depression, in mothers of emotionally handicapped children are so common that we may safely state that mothers of handicapped children need help in order to deal with their problems; let alone those of their children. To begin with, we should not overlook the elementary fact that mothers of handicapped children often hold attitudes towards them, which are widely divergent from reality. It is advisable that all mothers should receive frequent opportunities to discuss their problems with appropriate professional personnel, so that they may realize that their problems are not unique but common to most parents of handicapped children.

The emotional problems of mothers fall into two major categories; the first group of maternal reactions stems from a lack of adequate knowledge concerning the handicapped child. Mother's need to know a great deal about the condition of the handicapped; too often they have a loads of faulty information that needs to be corrected. If there are no deep-seated personality changes in the mother and no severe maladaptive behavioral reactions, the mother essentially needs a very carefully designed educative program (or guidance). At the same time, of course, attention must be paid to her feelings and emotional reactions.

In the second broad type of maternal reactions, the mother does develop significant personality changes and resultant maladaptive behavior. She may, for example, develop severe depression. In such cases, an educative or guidance approach is not adequate to help her resolve her problems; in fact more intensive help such as that offered by psychotherapy, is needed.

The mothers of children, who learn about the condition of their offspring early, tend to be more free and easy about the child. On the other hand, the mothers who learn about their children's disabilities later, because of them being milder and less obvious, are more difficult to treat.

The mother's adjustment intervention can be concluded in this manner:

- Information in order to understand and make sense of what is happing and how to plan and manage them through accurate sources.

- Sharing feelings with significant others, family friends and other parents of children with similar disabilities.

- Maintain and support by continuous follow up.
- Update and adequate written information regarding disabilities and problems concerning the baby.

- Reassure the parents about their reactions that they are common and normal and need to be aired.

\section{REFERENCES}

[1] Metalsky, G.I., Abrason. L. Y., Seligman, M.E.P., Semmel, A, \& Peterson, C.R. (1982), Attributional styles life events in the classroom: Vulnerability \& invulnerability to depressive mood reactions. J. Pers. Soc. Psychos. 43, 612-617.

[2] Petersen, A.C., and Hamburg, B.A. (1986). Adolescence. A developmental approach to problems and psychopathology: Behavior therapy, 17, 480-499.

[3] Lamb. M.E. (1977c). Father-infant \& mother-infant interaction in the first year of life child development, 48, 167-181.

[4] Murphy, E. (1982). Social origins of depression in old age. British journal of psychiatry 141:135-142.

[5] Watson, R.L. \& Midlarsky, E. (1979). Reactions of mothers with mentally retarded child, a social perspective.

[6] Eugene, A.L. (1978) helping parents help their children. New York. Brunner, Mazel publishers.

[7] Lurie L.A. Endocrinology \& the understanding \& treatment of the exceptional child journal of American medical Association, Vol. Cx may 7, 1938.

[8] Brown, George. W, (1993). Life events and affective disorder: Replications and limitations. Psychosomatic medicine, 55, 248-259.

[9] Buchwald, A.M., Coyne, J.C., \& Cole, C.S, (1978). A Critical evaluation of the learned helplessness model of depression J. Abnormal Psychology. 87, 180-193.

[10]Bolton, Oakley K, W. (1985). A Social-Cognitive theory of depression in reaction to life events. Psychological Review 22: 372-388.

[11] Abramson, L.Y. Seligman, M.E.P., \& Teasdale, J.D. (1978). Learned helplessness in humans, Critique \& reformulation. Journal of Abnormal Psychology; 87, 49-74. 